\title{
Erector Spinae
}

National Cancer Institute

\section{Source}

National Cancer Institute. Erector Spinae. NCI Thesaurus. Code C52902.

A group of three muscles (iliocostalis, long issimus, and spinalis) that orig inate at the sacrum, ilium, and lumbar vertebrae spines and insert into the ribs and vertebra in order to extend the vertebral column. 